\title{
On the Mechanism of Action of Prolylcarboxypeptidase
}

\author{
B. Shariat-Madar ${ }^{1}$, M. Taherian ${ }^{2}$ and Z. Shariat-Madar ${ }^{3}$ \\ ${ }^{1}$ College of Literature, Science, and the Arts, University of Michigan, Ann Arber, MI, \\ 2Department of Anesthesia, Massachusetts General Hospital, \\ Harvard Medical School, Boston, MA, \\ ${ }^{3}$ School of Pharmacy, Department of Pharmacology, \\ University of Mississippi, University, MS,
}

USA

\section{Introduction}

Many mechanisms are involved in the regulation of blood pressure. Among the molecules, hormones, and factors known to be involved in blood pressure regulation, PRCP can generate the most potent inflammatory vasodilator molecules, including nitric oxide (Zhao et al., 2001c), prostaglandins (Kolte et al., 2011), bradykinin (BK)-(Chajkowski et al., 2010) and angiotensin 1-7 (Ang $1-7)$-(Mallela et al., 2008) dependent pathways in the endothelium and astrocytes. Experimental evidence suggest that PRCP appears to metabolize its main substrates, des-Arg9-bradykinin (des-Arg9-BK, BK 1-8)(Chajkowski et al., 2010) and alphamelanocyte stimulating hormone 1-13 $\left(\alpha-\mathrm{MSH}_{1-13}\right)$ (Wallingford et al., 2009), to prevent the production of prostaglandins and NO, indicating that the enzyme may promote antiinflammatory effects in cardiovascular and cerebrovascular systems. Evidence shows that Prcp gene expression is elevated in the developing murine brain vasculature during the intermediate phase of chick chorio-allantoic membrane (CAM)(Javerzat et al., 2009), suggesting that PRCP has a role during the active phase of vascular remodeling. Interestingly, Prcp gene is overexpressed in glioblastoma and it is suggested that PRCP also has a role in tumor angiogenesis(Javerzat et al., 2009). Thus, PRCP plays important roles in response to stress and may be an endothelial gate-keeper regulating blood flow, which tightly regulates endothelial barrier function. The historical perspective of knowledge of PRCP and its roles in physiological and cardiovascular diseases such as inflammation, hypertension, thrombosis, and obesity is tabulated in Table 1.

\section{Cardiovascular system function}

The cardiovascular system is composed of the heart, blood, and a complex network of blood vessels. Humans have a closed cardiovascular system in which the system allows a complete separation of function and blood loss due to having a relatively low blood volume compared to species with open cardiovascular systems. In a closed cardiovascular system, blood flows rapidly from arteries to capillaries and returns through the venous system. The heart sustains the high pressure necessary for the blood to reach the body's tissues. 


\begin{tabular}{|c|c|c|}
\hline Year & & References \\
\hline 1971 & Human PRCP (EC 3.4.16.2) was found in biological fluids & (Sorrells and Erdos, 1971) \\
\hline 1978 & $\begin{array}{l}\mathrm{PRCP} \text { was purified from human kidney and its potential substrates } \\
\text { was reported. The two substrates were angiotensin II, and } \\
\text { angiotensin III }\end{array}$ & (Odya et al., 1978) \\
\hline 1981 & A novel and rapid radioassay for PRCP was developed & (Skidgel et al., 1981) \\
\hline 1981 & $\begin{array}{l}\text { PRCP was found in both inflammatory exudates and in cells that } \\
\text { appear at sites of inflammation }\end{array}$ & (Kumamoto et al., 1981) \\
\hline 1990 & $\begin{array}{l}\text { Cultured Madin-Darby canine kidney (MDCK) distal tubular cells } \\
\text { was found to contain PRCP }\end{array}$ & (Deddish et al., 1990) \\
\hline 1993 & $\begin{array}{l}\text { Human PRCP was sequenced and cloned. It was noted that PRCP } \\
\text { might have both exopeptidase and endopeptidase activities }\end{array}$ & (Tan et al., 1993) \\
\hline 1994 & $\begin{array}{l}\text { PRCP was found to have a modulatory role in the angiotensin II- } \\
\text { induced pulmonary vasoconstriction }\end{array}$ & (Tamaoki et al., 1994) \\
\hline 1995 & PRCP was found in monkey kidney & (Suzawa et al., 1995) \\
\hline 1995 & $\begin{array}{l}\text { PRCP was purified from cell free extracts of Xanthomonas } \\
\text { maltophilia, a bacteria species which is normally found in clinical } \\
\text { specimens }\end{array}$ & (Suga et al., 1995) \\
\hline 1995 & PRCP was found to be highly active in macrophages & (Jackman et al., 1995) \\
\hline 1997 & Watson and associates described localization of Prcp gene & (Watson, Jr. et al., 1997) \\
\hline 2002 & PRCP was found to be an endothelial cell prekallikrein activator & (Shariat-Madar et al., 2002) \\
\hline 2002 & $\begin{array}{l}\text { Moreira and associates described the extracellular PRCP that } \\
\text { activates prekallikrein }\end{array}$ & (Moreira et al., 2002) \\
\hline 2005 & $\begin{array}{l}\text { Overexpression of PRCP on Chinese hamster ovary cells was } \\
\text { reported }\end{array}$ & (Shariat-Madar et al., 2005) \\
\hline 2006 & $\begin{array}{l}\text { Wang and associates described the functional significance of PRCP } \\
\text { in the etiology of preeclampsia }\end{array}$ & (Wang et al., 2006) \\
\hline 2007 & $\begin{array}{l}\text { Hooley and associates described a C-terminal extension in the PK } \\
\text { serine protease domain as a potential substrate for PRCP. }\end{array}$ & (Hooley et al., 2007) \\
\hline 2009 & $\begin{array}{l}\text { Wallingford and associates described that Prcp-null mice had } \\
\text { elevated levels of alpha-MSH1- } 13 \text { in the hypothalamus and were } \\
\text { leaner and shorter than the wild-type controls on a regular chow } \\
\text { diet. Prcp null mice were also resistant to high-fat diet-induced } \\
\text { obesity }\end{array}$ & (Wallingford et al., 2009) \\
\hline 2009 & $\begin{array}{l}\text { Soisson and associates described the crystal structure of human } \\
\text { PRCP }\end{array}$ & (Soisson et al., 2010) \\
\hline 2009 & $\begin{array}{l}\text { E112D polymorphism in the prolylcarboxypeptidase gene was } \\
\text { found to be associated with blood pressure response to benazepril } \\
\text { in Chinese hypertensive patients }\end{array}$ & (ZHANG Yan et al., 2009) \\
\hline 2009 & $\begin{array}{l}\text { Javerzat and associates described overexpression of PRCP during } \\
\text { the intermediate phase of the chick chorio-allantoic membrane }\end{array}$ & (Javerzat et al., 2009) \\
\hline 2010 & $\begin{array}{l}\text { Recombinant PRCP (rPRCP) metabolized } \mathrm{BK}_{1-8} \text { to } \mathrm{BK}_{1-7} \text {, whereas } \\
\text { rPRCP was ineffective in metabolizing BK } 1-9\end{array}$ & (Chajkowski et al., 2010) \\
\hline 2010 & PRCP was found to be active in human cerebrospinal fluid & (Zhao et al., 2010) \\
\hline 2010 & $\begin{array}{l}\text { Overexpression of angiotensin type } 2 \text { (AT2) receptor in mouse } \\
\text { coronary artery endothelial cells was found to increase expression } \\
\text { of } \mathrm{PRCP} \text {, which may contribute to kinin release }\end{array}$ & (Zhu et al., 2010) \\
\hline 2011 & $\begin{array}{l}\text { PRCP is a } 4 \text { OHTAM resistance factor in estrogen receptor-positive } \\
\text { breast cancer cells }\end{array}$ & (Duan et al., 2011) \\
\hline 2011 & PRCPgt/gt mice were found to be hypertensive and prothrombotic & (Adams et al., 2011) \\
\hline
\end{tabular}

Table 1. Historical Perspective 
To deal with proper delivery of blood to the tissues as well as many types of insults, including chemical and physical damage as well as infection, the cardiovascular system has evolved an intricate multilayer of specialized biochemical pathways. Multiple feedback mechanisms controlling blood flow with contrasting effects regulate normal vascular function, which have either stimulatory or inhibitory effects. These features enable the cardiovascular system to perform its tasks effectively. Of these regulatory feedback machinery, a few have multiple and redundant control mechanisms that tightly uphold cardiovascular functions. Among these regulatory feedback mechanisms within the mammalian cardiovascular system, we review the renin-angiotensin(Savinetskaia et al., 2008; Hayashi et al., 2010), kallikrein-kinin(Bryant and Shariat-Madar, 2009; Saxena et al., 2011), and pro-opiomelanocortin (POMC) (Wang et al., 2008) systems that communicate with each other. Although within each of these systems are surely a network of molecular interactions with other pathways, their interactions are not either compared or reviewed. However, special attention is given to the role of PRCP in health and disease.

\subsection{Renin-angiotensin system (RAS)}

The systemic RAS is a complex, but fairly well understood pathway(Perret-Guillaume et al., 2009; Molteni, 1982; Brown et al., 1983; Oishi et al., 1996; Renshaw et al., 2001; Hettinger et al., 2002; Volzke et al., 2005; Clerk et al., 2005). Although the physiological importance of the RAS for regulation of blood pressure and water homeostasis has been established(Fukuchi et al., 1973; Bing and Nielsen, 1973), emerging evidence suggests that the components of RAS are important players for maintenance and regulation of many physiological and pathophysiological processes, such as angiogenesis (Abali et al., 2002), inflammation (Akishita et al., 2001), tumorigenesis(Ager et al., 2008), thrombosis (Asselbergs et al., 2008; Asselbergs et al., 2007), vascular hypertrophy (Brede et al., 2001), vascular development (Lasaitiene et al., 2006), and remodeling (Akishita et al., 2000; Alcazar et al., 2009). The molecular mechanisms by which the components of RAS exert their pleiotropic effects are redundant in order to ensure an appropriate balance between the stimulatory and inhibitory signals favoring normal blood delivery. More interestingly, there is also a balance between RAS function and its counter-regulatory hormones, in particular plasma kinins, the main effectors of the plasma Kallikrein-Kinin System (KKS) (Shariat-Madar et al., 2002a). The active metabolites of these two systems regulate each other in an antagonistic manner. In view of the opposing effects of these two systems(Bader, 2001), the complex interplay of RAS and KKS with the local microenvironment of endothelial cells lining blood vessels is responsible for delivering nutrients. The RAS and KKS signaling pathways are also responsible for sustaining the high pressure necessary for the blood to reach all of the tissues of the body while maintaining blood pressure within a narrow range.

The RAS encompasses numerous peptides that act in concert in a cascade triggered by low blood volume or a drop in blood pressure cascades or water-fall(Taquini, Jr. and Taquini, 1961; Nicholls and Robertson, 2000; Shariat-Madar and Schmaier, 2004; Ritz, 2005; Oudart, 2005). These peptides exert their actions, which can be autocrine (Chan and Wong, 1996), paracrine (Haulica et al., 2005), or endocrine(Gohlke et al., 1992), acting through specific cell surface receptors on their target cells to control blood pressure and body fluid homeostasis. In a stepwise enzymatic process, the aspartyl protease renin (a rate-limiting enzyme) cleaves circulating angiotensinogen to the inactive angiotensin I (Ang I) (Helmer, 1965). Subsequently, 
angiotensin converting enzyme (ACE) cleaves the two C-terminal amino acid residues of Ang I to generate the key effector of RAS, angiotensin II (Ang II, Ang 1-8) under physiological conditions (Figure 1)(Peart, 1975). However, the tonin-, cathepsin G-, tissue plasminogen activator- or chymase-induced Ang II generation is apparently important under pathophysiological conditions (Doggrell and Wanstall, 2004; Doggrell and Wanstall, 2003; Leckie, 2005; Belova, 2000). Recent evidence suggests that Ang I can block a downstream protease, PRCP in vitro (Mallela et al., 2008). Up to now, the physiological significant role of Ang I in blocking PRCP is uncertain. Ang II primarily exerts its physiological effects by activating angiotensin type 1 (AT1) receptors (Figure 1) (Chassagne et al., 2000). However, angiotensin type 2 (AT2) receptors also appear to mediate Ang II effects (Figure 1)(Anavekar and Solomon, 2005). Activation of this signaling pathway leads to cardioprotection. Both AT1 and AT2 belong to the G-protein couple receptor (GPCR) superfamily(Ali et al., 1997a). While AT1 can couple to two members of the $G \alpha$ family $\left(G_{\alpha q} / 11\right.$ and $\left.G_{\alpha i}\right)$ and to $G_{\beta \gamma}$ complexes (Okuda et al., 1996), AT2 can couple to $G_{\alpha i}$ and $G_{\alpha s}$ subunits (Kai et al., 1996).

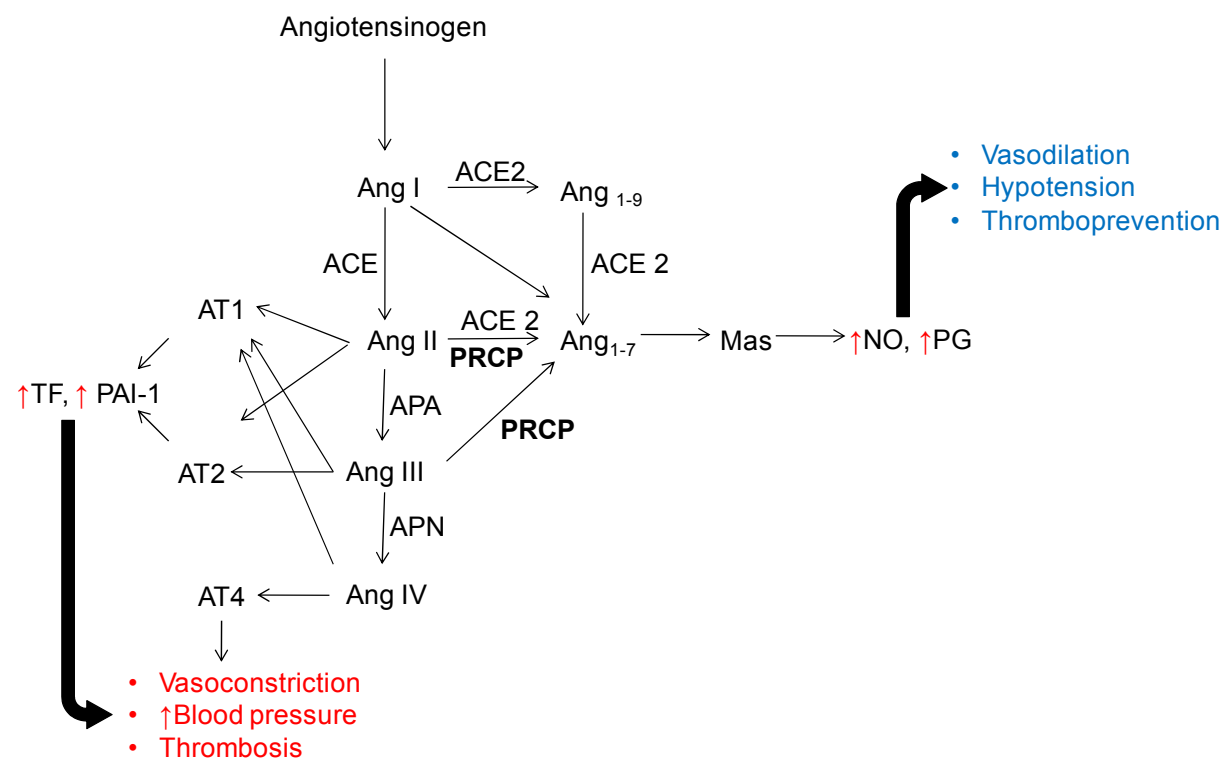

Fig. 1. Metabolites of the renin-angiotensin system influence cardiovascular system.

Ang I; Angiotensin I, Ang II; Angiotensin II, Ang III; Angiotensin III, Ang IV; Angiotensin IV, Ang 1-9; Angiotensin 1-9, Ang 1-7; Angiotensin 1-7, ACE; Angiotensin converting enzyme, ACE2; Angiotensin converting enzyme 2, AT1; angiotensin type 1, AT2; angiotensin type 2, AT4; angiotensin type 4, PAI-1; plasminogen activator 1, TF; tissue activator, Mas; Ang $_{1-7}$ Mas receptor, NO; nitric oxide, PG; prostaglandin.

Ang II-induced AT1 receptor-dependent vasoconstriction is mediated by activation of $G_{\alpha q / 11}, G_{\alpha i}$, and $G_{\beta \gamma} \operatorname{complexes(Kai~et~al.,~1996).~The~activation~of~these~heterotrimeric~} G$ proteins triggers the activation of phospholipase C (PLC)(Griendling et al., 1997) and phospholipase D (PLD)(Griendling et al., 1997; Ushio-Fukai et al., 1999), leading to an increase in intracellular calcium, actin-myosin interactions, and release of leukotrienes. 
Although AT2 appears to be cell-type specific with a low expression pattern in adult tissues, it is the dominate receptor in fetal tissues(Akishita et al., 1999; Guan et al., 2008). Experimental evidence in support of AT2-independent G-protein signaling pathway has been demonstrated (Bottari et al., 1991). AT2 receptors are essential for triggering vasodilation and it can also mediate cell death (Gwathmey et al., 2009). Ang II-induced AT2 receptor-dependent vasodilation is mediated by activation of nitric oxide/cyclic guanosine 3', 5'-monophosphate (cGMP) signaling cascades. On the other hand, AT2 activation by Ang II may lead to the activation of proapoptotic second messengers, MAPK phosphatase 1 (MKP-1)(Horiuchi et al., 1997), SH2 domain-containing phosphatase 1 (SHP-1)(Feng et al., 2002), and protein phosphatase 2A (PP2A)(Huang et al., 1996) and subsequent inactivation of MAPKs(Bedecs et al., 1997; Horiuchi et al., 1997), and ERK1/2(Horiuchi et al., 1997). While identification and characterization of the molecular switch that controls differential activation of distinct downstream signaling pathways by Ang II are poorly understood, our understanding of the downstream events is exponentially mounting.

In the next step of the RAS cascades, angiotensin converting enzyme 2 (ACE2) and PRCP metabolize Ang II (a prothrombotic risk factor) to angiotensin 1-7 (a vasodilator, antithrombotic factor)(Mallela et al., 2008), highlighting the functional significance of these two enzymes. Notably, ACE2 (Gurley et al., 2006) and PRCP (Adams et al., 2011)null mice do not exhibit excessive elevated blood pressure compared to control littermates, suggesting that these enzymes play a critical role in the maintenance of normal vascular physiology, Figure 1. PRCP also metabolizes angiotensin III (Ang III, Ang2-8) to angiotensin 2-7 (Ang 27)(Mallela et al., 2008). Ang III, like Ang II, is also a pressor agent whose response is mediated by $\mathrm{AT}_{1}$ receptors (Campbell et al., 1979). Ang III is implicated in cell proliferation and matrix accumulation(Ruiz-Ortega et al., 1998). Ang II- and Ang III-induced $\mathrm{AT}_{1}$ receptor stimulation mediate vasoconstriction, mitogenic and hypertrophic effects and inflammatory responses (Ishanov et al., 1998; Schluter and Wenzel, 2008; Marshall et al., 2000). Hydrolysis of Ang III by PRCP leads to a decrease in Ang III-mediated effects, further pointing out the importance of PRCP in contributing to regulation of blood pressure.

\subsection{RAS and angiogenesis}

Ang II is a proangiogenic hormone and AT1 mediates its proangiogenic actions(Wilop et al., 2009). The proangiogenic effect of Ang II leads to upregulation of EGF (Friedlander and Terzi, 2006; Lautrette et al., 2005), $\beta F G F$ (Liu et al., 2009), PDGF(Blaschke et al., 2002; Li et al., 2005), IGF-1 (Kajstura et al., 2001; Song et al., 2005(Jia et al., 2011), hepatocytes growth factor(Bataller et al., 2003), and NO(Abassi et al., 1997). Ang II-induced AT1 mediated signaling pathway cause an activation of mitogen-activated protein kinases (MAPK) (Guo et al., 2006; Morrell et al., 1999; Taniyama et al., 2004).

The MAPK pathway induces cellular protein synthesis, volume regulation, gene expression, and growth (Morrell et al., 1999). In contrast, activation of AT1-independent G-protein signaling pathway by Ang II can also cause endothelial cell proliferation through non-receptor tyrosine kinase Src-mediated increase of NADP oxidase activation, phosphorylation of extracellular signal-regulated kinases 1 and 2 (ERK1/2), P38 MAP kinase, and a decrease in phosphorylation of Src homology 2 (SH2)-containing inositol phosphatase 2 (SHIP2)(Ali et al., 1997b; Feng et al., 2002; Bedecs et al., 1997). These experimental observations suggest that Ang 
II is proangiogenic. However, evidence suggests that Ang II may inhibit angiogenesis under certain conditions by activating AT2-receptors, suggesting that AT1 mediates effects that counteract those mediated by AT2 receptors (Chung et al., 1996).

\subsection{RAS in cardiovascular disease}

Since Ang II, Ang III, Ang IV, and Ang 1-7 can act systemically and locally to control blood pressure and body fluid homeostasis, components of RAS have become therapeutic targets for diseases such as hypertension(Farmer, 2000), cardiac hypertrophy(Brasier et al., 2000; Billet et al., 2008), congestive heart failure(Volpe and De, 2000; Yang et al., 1998), ischemic heart disease(Burrell et al., 2005), coronary heart disease(Farmer and Torre-Amione, 2001), and renal diseases.

\section{Plasma kallikrein kinin system (KKS)}

The primary functions of plasma KKS are to 1) assist hemostasis and limit blood loss, 2) increase capillary permeability and dilate arterioles, 3) promote antiatherogenic and antithrombogenic properties of endothelium by maintaining or increasing antiatherogenic agents including nitric oxide, prostaglandins, and tissue plasminogen activator, and 4) induce acute vascular pain. In addition to its hemodynamic actions, antifibrotic and renoprotective effects of kallikrein have been reported (Pawluczyk et al., 2008). Although the expression and activity of components of plasma KKS are known to be age-dependent (Gordon et al., 1980) for three decades, the mechanism underlying this phenomenon is yet to be unravelled.

The components of KKS, also called the contact activation pathway, consist of three serine zymogens (prekallikrein, factor XII, and factor XI) as well as a kinin and antiangiogenic precursor (high molecular weight kininogen)(Figure 2)(Ratnoff and Saito, 1979). Plasma kallikrein, a serine protease, is synthesized in the liver. It is predominantly secreted by hepatocytes as an inactive molecule called prekallikrein (PK) that circulates in plasma as a heterodimer complex bound to high molecular weight kininogen (HK) with 1:1 molar stoichiometry. PK is a single chain a-globulin that is present in the plasma of humans and of other animal species. About $80-90 \%$ of PK is normally in complexed with HK.

$\mathrm{HK}$ is a single-chained glycoprotein synthesised by liver and secreted into the circulation (Sueyoshi et al., 1987). HK consists of three domains: an amino acid-terminal heavy chain, a carboxyl-terminal light chain, and bradykinin moiety (Figure 3)(Kleniewski et al., 1988). The heavy chain linked to the light chain by a single disulfide bond (Kleniewski et al., 1988). Domain 6 of HK has a PK and FXI-binding site (Reddigari and Kaplan, 1989). HK binding to cell surface proteins or artificial surfaces is vital for activation of the plasma KKS(Pixley et al., 2011; Joseph et al., 2001; Zhao et al., 2001). The procoagulant activity of HK is dependent on whether it is in complexed with PK or FXI (Gailani and Broze, Jr., 1991). The proteolytic cleavage of HK by kallikrein results in the production of BK and cleaved HK (HKa). HK could be metabolized by activated factor XI into three peptide fragments, yet its physiological significance has been unclear. HK is involved in angiogenesis and in cell adhesion and the matrix of various endothelial cells (Motta et al., 2001).

Unlike PK, factor XI (FXI) is involved in normal hemostasis in vivo. FXI synthesis is primarily in the liver. Factor XI activity is age-dependent (Andrew et al., 1987). While its activity is low at 
birth, FXI levels are reached to normal adult plasma levels by six months of age. FXI circulates in the plasma as a disulfide bond-linked dimer complexed with HK. It is important for propagation of blood coagulation(Walsh and Griffin, 1981). FXI can be activated to activated FXI (FXIa) by FXIIa-mediated activation on the negatively charged surfaces or thrombinmediated activation on the platelet surface(Baglia et al., 2004), Figure 2. FXIa augments thrombin generation via interaction with a coagulation factor of the extrinsic pathway, factor IX(Baglia and Walsh, 1998; Taketomi et al., 2008). It appears that FXI along with activated platelet are a prerequisite for optimum thrombin generation in which the procoagulant activity of KKS is so just below the threshold point (Keularts et al., 2001).

Plasma KKS activation has been demonstrated under physiological conditions and in numerous inflammatory human diseases. Under pathological conditions, conversion of plasma factor XII (FXII) to its active form (FXIIa) is concomitant with the appearance of hematologic responses including coagulation, fibrinolytic, and inflammation. FXIIa initiates propagation of the intrinsic pathway (IP) of blood coagulation via factor XI activation, Fig. 2 (1; Pathway 1). In the presence of HK, FXIIa converts plasma prekallikrein (PK) to kallikrein, Fig. 2 (2; Pathway 2). In a reciprocal feedback mechanism, kallikrein accelerates FXII activation. Kallikrein causes the release of tissue plasminogen activator (tPA) via a bradykinin-dependent pathway.

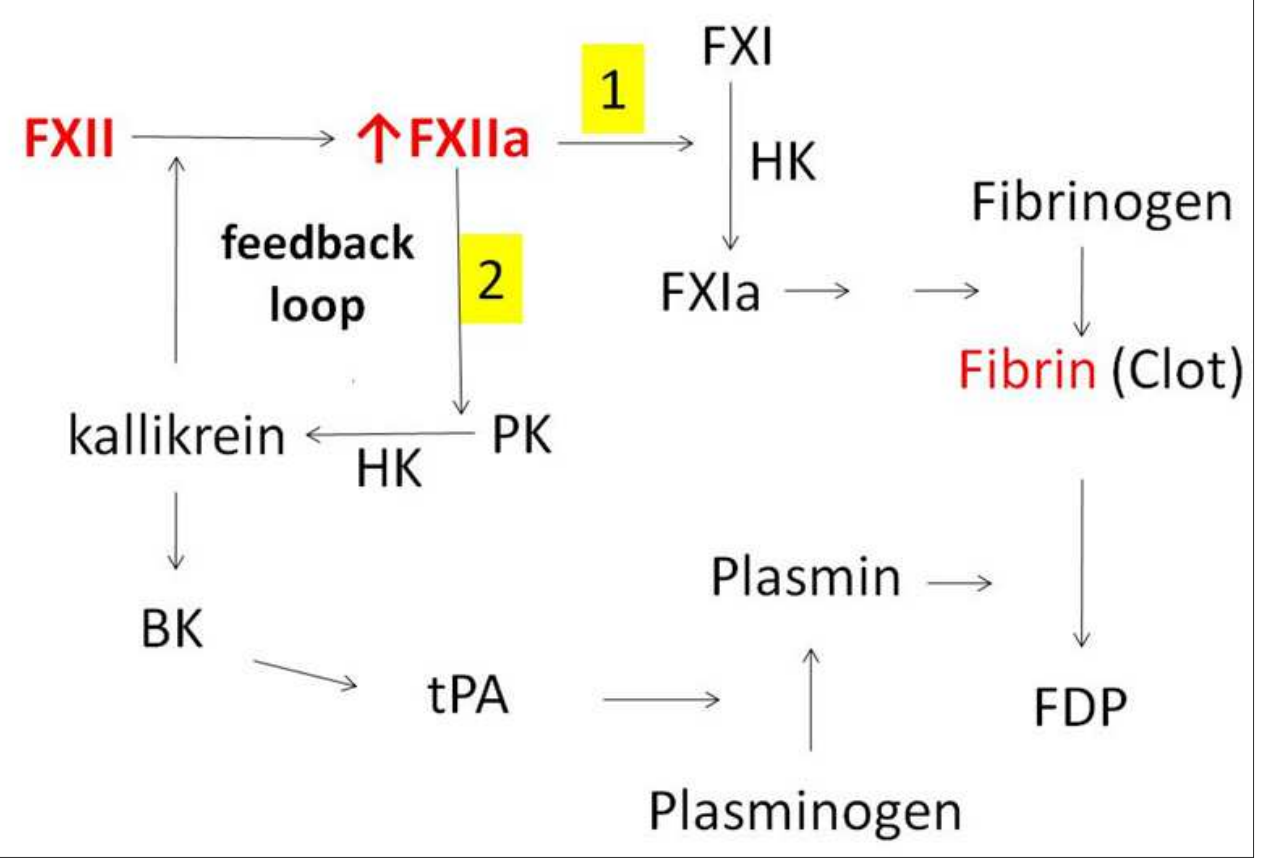

Fig. 2. A schematic representation of factor XII (FXII) activation during pathological plasma proteolytic states. FXIIa; activated factor XII, 1; pathway 1, FXI; factor XI, FXIa; activated factor XI, 2; pathway 2, HK; high molecular weight kininogen, PK; prekallikrein, BK; bradykinin, tPA; tissue plasminogen activator, FDP; Fibrin degradation Products. 
Fibrinolysis is the process by which plasmin digests fibrin, Fig. 2. This aids in thrombus (clot) dissolution and limits the promotion of coagulation (clot formation). tPA converts plasma plasminogen to plasmin, which in turn remodels the thrombus. Plasmin breaks down the clot fibrin to fibrin degradation products (FDP). Consequently, FDP blocks thrombin-induced fibrin (clot) formation, Figure 2. Notably, plasmin triggers a positive feedback amplification by accelerating conversion of PK to kallikrein.

Kallikrein acts on HK to generate HKa (cleaved HK) and bradykinin (BK), Figure 3. BKinduced activation of the $\mathrm{B} 2\left(\mathrm{~B}_{2}\right)$ receptor leads to the formation of tissue plasminogen activator (tPA, a potent fibrinolytic molecule)(Czokalo-Plichta et al., 2001), Fig. 3. BK upon activation of its constitutive $B_{2}$ receptors on endothelial cells leads to an increase in intracellular $\mathrm{Ca}^{2+}$ levels and subsequent production of nitric oxide (NO, a vasodilator) and prostacyclin ( $\mathrm{PGI}_{2}$, a platelet activation inhibitor), ultimately leading to vasodilation, increased vascular permeability and edema (Zhao et al., 2001b; Hong, 1980; Palmer et al., 1987). Whereas $B_{2}$ receptors are constitutively expressed, the expression of bradykinin $B 1$ $\left(B_{1}\right)$ receptors is induced during inflammation (Marceau, 1995). Metabolism of BK by carboxypeptidase $\mathrm{N}(\mathrm{CPN})$ in plasma or carboxypeptidase $\mathrm{M}(\mathrm{CPM})$ on endothelial cells yields des-Arg9-BK which interacts with $B_{1}$ receptors to potentiate and/or perpetuate the inflammatory response (Figure 3)(Marceau et al., 1981).

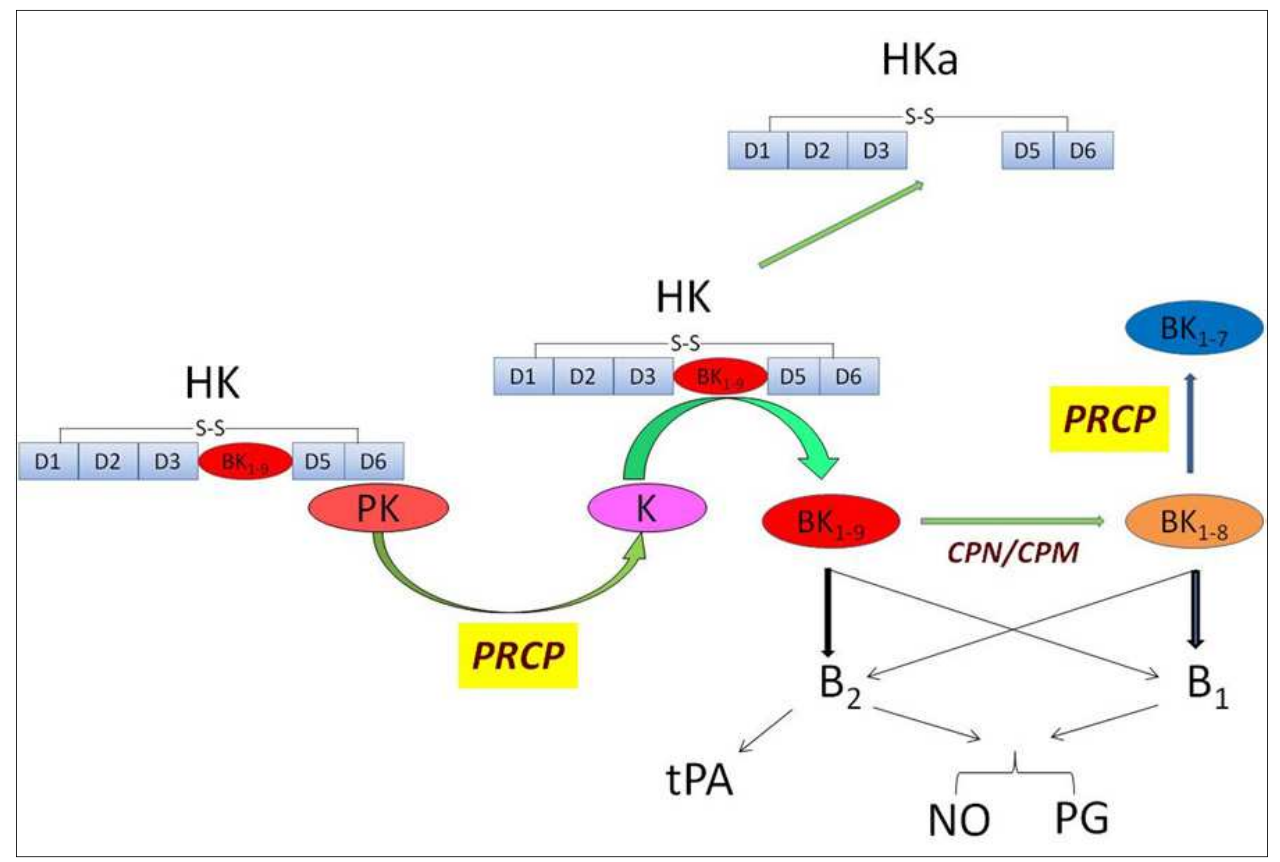

Fig. 3. A schematic representation of PRCP-dependent prekallikrein activation. HK; high molecular weight kininogen, PK; prekallikrein, PRCP; prolylcarboxypeptidase, K; kallikrein, BK 1-9; bradykinin, HKa; cleaved HK, BK; bradykinin, NO; nitric oxide, PGI2; prostacyclin, tPA; tissue plasminogen activator, CPN; carbox peptidase N, CPM;

Carboxypeptidase M, BK $\mathbf{1}_{\mathbf{1 - 8}}$; bradykinin 1-8 (des-Arg9-bradykinin), BK $\mathbf{B K}_{\mathbf{1}-7}$; bradykinin 1-7. 
Under physiological conditions, PK bound to HK on endothelial cells can lead to PK activation through a FXIIa-independent mechanism, which in turn leads to BK generation. While assembly and activation of the plasma KKS is regulated by PRCP on several cultured cell lines, heat shock protein 90 (HSP90) is the main activator of the plasma PK in mesothelium-derived cell lines (Varano, V et al., 2011). Thus, the plasma KKS participates in both surface-dependent activation of blood clotting and inflammatory process. Further, PRCP participates in cell surface - dependent activation of PK and its dependent pathways. The question remains how PRCP-dependent PK signaling pathway is assembled, activated, and regulated in response to plasma levels of Ang II and/or Ang III. However, in an elegant study, the authors find evidence for a cross-talk among the kinin, PRCP, and angiotensin signaling pathways(Zhu et al., 2010).

\subsection{The plasma KKS and cardiovascular diseases}

Whereas the normally functioning KKS can successfully counteract blood pressure, promote smooth blood flow, modulates neovascularisation and eliminates pathogens by promoting the recruitment of neutrophils to the site of injury, inappropriate responses can lead to extensive tissue damage. KKS has been implicated in the pathogenesis of inflammation, hypertension, endotoxemia, and coagulopathy. Increased BK levels is a hallmark in all of these cases. In some cases, the persistent production of BK due to the deficiency of the blood protein C1-inhibitor, which controls kallikrein and activated FXII, is detrimental to the survival of the patients with hereditary angioedema (HAE). In others, the inability of angiotensin converting enzyme (ACE) to degrade BK leads to elevated BK levels and edema in patients on ACE inhibitors.

\subsection{The importance of KKS for angiogenesis}

Various cancers exhibit upregulation of either epidermal growth factor or urokinase receptor or both, which leads to poor prognosis. On studies done on human prostate cancer cells (DU145) the cleaved fragment of HK, HKa and also domain 5 prevented colocalization of UPAR and EGFR, decreased downstream extracellular signal-regulated kinase (ERK) and AKT-mediated signal transduction at EGFR(Wuepper and Cochrane, 1972). This indicates therapeutic potential of HKa and D5 to inhibit metastasis involving migration and invasion of human prostate cancer cells.

Both HK and LK are proangiogenic as demonstrated by induction of vascularization on chorioallantoic membrane. Monoclonal antibody directed against HK has been shown to inhibit HK-induced neovascularization on chorioallatoic membrane as well as HK-induced fibrosarcoma formation. Domain 5 of $\mathrm{HK}$, also called kininostatin, is antiangiogenic(Colman et al., 2000). There are reports that peptides derived from domain 3 and domain 5 inhibit angiogenesis in $\mathrm{Zn}^{2+}$ independent and dependent manner (Zhang et al., 2002). Antibody directed against domain 5 also prevents neovascularization(Song et al., 2004).

Like HK, BK also is proangiogenic and a reduction in its levels may be associated with impaired neovascularization(Krankel et al., 2008). But HKa is antiangiogenic as it prevents VEGF and FGF2 induced vascularization. HKa through its D5 domain has been shown to inhibit sphingosine 1-phosphate (S1P) and vascular endothelial growth factor (VEGF) mediated endothelial cell migration by modifying PI3 kinase-Akt signaling (Katkade et al., 
2005). HKa acting through uPAR can also bring about apoptosis in endothelial cells, which is due to inhibition of uPA binding to uPAR thus preventing subsequent uPAR internalization and regeneration to the cell surface (Cao et al., 2004). This results in interference with all aspects of angiogenesis such as cell migration, proliferation, and survival.

Histidine proline rich glycoprotein (HPRG) is present in plasma abundantly and might be the predecessor of HK(Koide and Odani, 1987). HPRG is similar in sequence and function to HKa and is shown to bind to tropomyosin and inhibit angiogenesis through apoptosis (Donate et al., 2004).

\section{Pro-opiomelanocortin (POMC)}

POMC is expressed in numerous mammalian tissues (Tatro et al., 1992; Tatro and Reichlin, 1987). It undergoes extensive posttranslational modification by a family of serine proteases and the prohormone convertases (PCs). The metabolism of POMC results in the generation of alpha-melanocyte stimulating hormone ( $\mathrm{a}-\mathrm{MSH}, \alpha-\mathrm{MSH}_{1-13}$ ) along with $\beta-\mathrm{MSH}, \gamma-\mathrm{MSH}$, and $\beta$-endorphin (Shariat-Madar et al., 2010). Although all four of these hormones are important, only $\alpha-\mathrm{MSH}_{1-13}$ will be discussed here. The synthesis of $\alpha-\mathrm{MSH}_{1-13}$ from POMC involves numerous specific enzymes in addition to PC1 and PC2. It appears that PRCP plays an important role in regulating $\alpha-\mathrm{MSH}$.

\section{The interactions among KKS, RAS, and POMC}

The participation of the components of the plasma kallikrein-kinin system in some pathological processes like hypertension and cardiovascular diseases is still a matter of controversy. The availability of transgenic and knock-out mice for B2 and B1 receptors and angiotensinogen and angiotensin II receptors have advanced our understanding about the roles of KKS and specifically these receptors in cardiovascular regulation and inflammatory processes.

Bradykinin (BK) is the natural hypotensive agent that causes vasodilatation by stimulation of endothelial B2 receptors of arteries and arterioles, and the subsequent endothelial release of nitric oxide and prostaglandins(Sharma, 2009). BK influences the kidneys to produce diuresis and natriuresis (Katori and Majima, 2008; Katori and Majima, 2003). The diuretic effect of the exogenous BK administered by the renal artery is by $\mathrm{B}_{2}$ receptors (Boric et al., 1998; Croxatto et al., 1999), whereas the BK-induced natriuresis and increase in renal blood flow are due to both $B_{1}$ and $B_{2}$, Figure 3 (Lortie et al., 1992). Tissue injury such as myocardial ischemia and inflammation can cause the expression of B1 receptors on their surfaces (Foucart et al., 1997b; Foucart et al., 1997a). In addition, elevated concentrations of BK have been observed in ischemic myocardium(Burch and DePasquale, 1962; Burch and DePasquale, 1963). Occlusion of the proximal left anterior coronary artery causes a change in BK(Hashimoto et al., 1979; Kimura et al., 1973; Hashimoto et al., 1977). Exposure of the epicardium of anesthetized dogs to BK leads to stimulation of sympathetic afferent fibers protruding into the left ventricle(Uchida and Murao, 1974). Inhibition of the $B_{2}$ receptor inhibitor resulted in increased kallikrein activity, but not kallikrein mRNA levels, in kidney of adult rats. There is a direct correlation between increased renal interstitial BK levels in dogs in low-sodium balance and the presence of $B_{2}$ receptors(Siragy et al., 1997). There is 
also evidence that kinin or $\mathrm{B}_{2}$-receptor inhibitor administration increases renin secretion or decrease plasma renin levels in anesthetized rabbits, respectively(Chiu and Reid, 1997). This data plus the location of $B_{2}$ receptors in different parts of the kidney and vascular endothelium suggests a role for the plasma KKS in the cardiovascular system (Schricker et al., 1995).

There have been numerous suggestions that kallikrein converts prorenin to renin and a few results suggest that RAS and KKS are interdependent and KKS regulates RAS activity (Sealey et al., 1979). In this report, the plasma prorenin was activated to renin in vitro by kallikrein when plasma acidity increased (Sealey et al., 1979). Later, Purdon and colleagues evaluated the effect of kallikrein converting prorenin to renin in plasma deficient in $\mathrm{C} 1$ inhibitor (hereditary angioedema) at neutral pH(Purdon et al., 1985). Although PK was completely activated to kallikrein and despite normal prorenin concentration, prorenin was not converted to an active enzyme. Regardless of kallikrein metabolic capability in converting prorenin to renin, studies suggest the presence of a crosstalk between the vasoconstricting RAS and the vasodilating KKS(Yokosawa et al., 1979).

In summary, the increased activity of RAS could be responsible both for arterial wall constriction and KKS activation and subsequent BK production to relief vasoconstriction. This explains the previous finding when the pressure is raised in the perfused heart muscle and brain, the flow can be held constant independently of any external neurogenic control(Mosher et al., 1964). The regulation of tissue flow as perfusion pressure changes can be affected by the rate of delivery or removal of BK and Ang II to the perfused region, influencing the state of contraction of the smooth muscle cells of the blocked vessels directly. This signifies the importance of the feedback mechanism between KKS and RAS. These systems may serve as a "on-off" biological switch impacting the risk of thrombosis/bleeding and those of low/high blood pressure.

\section{Prolylcarboxypeptidase or angiotensinase $\mathbf{C}$}

PRCP has a subtle role in preserving the blood flow through the endothelial lining of blood vessels so that the tissues can maintain cellular function. PRCP exerts this effect through regulation of local levels of autocrine-paracrine hormones such as angiotensin II (Ang II), angiotensin III (Ang III), and bradykinin generation via kallikrein-kinin pathway. Subsequently, the modification of these vasoactive substances influences the secretion or expression of a diverse group of endothelium mediators that are involved in the contraction and relaxation of smooth muscles, regulating blood flow, blood clotting, inhibition of platelet aggregation, and electrolyte homeostasis. It is well-established that dysfunction of endothelium significantly contributes to the development of thrombosis.

\subsection{Physiology}

PRCP is a serine peptidase that cleaves peptides at C-terminal amino acids linked to a proline residue. The first evidence that PRCP might play a role in the cardiovascular system was provided by catalytic activity analysis, which showed the metabolism of angiotensin II (Ang II) to angiotensin 1-7 (Ang 1-7)(Odya et al., 1978b). The mere inactivation of Ang II results in two events that broaden the functional spectrum of PRCP. First, it is a negative regulator of the pressor actions of the renin-angiotensin system (RAS). Second, PRCP 
activity provides a measure of endothelium relaxation due to its ability to initiate nitric oxide generation through Mas receptor activation (Silva et al., 2007). PRCP metabolizes angiotensin III (Ang III) to angiotensin 2-7 (Ang 2-7)(Odya et al., 1978c). Ang III is a pressor agent whose response, like that of Ang II, is mediated by $\mathrm{AT}_{1}$ receptors(Felix et al., 1991a; Gammelgaard et al., 2006b). We described that when the complex of high molecular weight kininogen (HK) and prekallikrein (PK, Fletcher factor) binds to endothelium membrane, PK is rapidly converted to kallikrein by PRCP, Figure 3(Shariat-Madar et al., 2002b). The formed kallikrein then cleaves HK to liberate bradykinin (BK), which leads to vasodilation and subsequent nitric oxide and PGI2 formation by activating constitutive bradykinin $\mathrm{B}_{2}$ and inducible bradykinin $B_{1}$ receptors (Zhao et al., 2001a; Colman and Schmaier, 1997). BK also causes release of tissue plasminogen activator (tPA, a profibrinolytic factor) to convert plasminogen to plasmin, which inhibits platelet aggregation, thrombus formation and promotes fibrinolysis, Figure 2(Pawluczyk et al., 2006). Thus, PRCP locally regulates nitric oxide-dependent vasodilation and indirectly modulates fibrinolysis within the vascular wall.

\subsection{Protein structure and molecular biology}

The human Prcp gene has been mapped to 11q14 and the gene is more than $147 \mathrm{~kb}$ in length and has 9 exons (Watson, Jr. et al., 1997). More recently, a new Prcp-like gene (Prcp2) has been discovered. The human Prcp gene family contains at least 2 genes. Both genes share important similarities including significant homology at the nucleotide level. Both genes encode for putative serine proteases. However, the functional role of Prcp 2 gene has not been characterized.

PRCP belongs to the single chain serine peptidase S28 family. It is derived from a larger precursor, prepro-PRCP, whose primary nucleotide structure was first described in a human cDNA clone by Tan et al., 1993. It appears that the precursor is homodimer polypeptides containing a secretory signal sequence. PRCP regulates the activity of bradykinin, Ang II, Ang III, prekallikrein, and $\alpha-\mathrm{MSH}(O d y a$ et al., 1978a; Shariat-Madar et al., 2002c; Moreira et al., 2002; Wallingford et al., 2009), suggesting that PRCP has versatile roles in influencing cardiovascular system. The enzyme is ubiquitously present in all major areas of the vascular bed as well as in the kidney, heart, placenta, and hypothalamus (Jackman et al., 1995b; Skidgel et al., 1981; Rosenblum and Kozarich, 2003; Schmaier, 2003; Shariat-Madar et al., 2010). However, PRCP is highly produced in endothelial cells, which is one cell type involved in the release of vasodilators and antithrombotic mediators.

\subsection{PRCP in cardiovascular diseases}

PRCP and angiotensin converting enzyme 2 (ACE2) are exopeptidases, which convert Ang II to Ang 1-7. ACE2 metabolizes AngII at a much faster rate than PRCP (Rice et al., 2004), suggesting that Ang II is a poor substrate for PRCP. Clinical studies have provided reliable evidence that ACE2 is an essential regulator of angiotensin I (Ang I), Ang II and angiotensin-induced cardiac hypertrophy (Huentelman et al., 2005). Increased myocardial levels of Ang II concomitant with a significant decrease in Ang 1-7 in ACE2 deficient hearts has been reported (Kassiri et al., 2009). These data suggest that PRCP may indeed be important in metabolizing Ang II in the absence of ACE2. These observations suggest that $\mathrm{PRCP}$ is a redundant catalyst contributing to alternate pathways for Ang II metabolism. 
Over thirty years ago, Odya et al (Odya et al., 1978d) showed that PRCP can metabolize Ang III to Ang 2-7. Evidence indicates that Ang 2-7 excites some neurons in the paraventricular nuclease (Ambuhl et al., 1992). Differential regulation of Ang 2-7 during ACE inhibitor treatment suggests a cardiovascular role for this peptide (Campbell et al., 1991). Because of the significance of Ang 2-7, AngIII regulation and metabolism are important. Results from several studies show that Ang III is a pressor agent. It exerts its hypertensive effects via $\mathrm{AT}_{1}$ receptors (Felix et al., 1991b; Gammelgaard et al., 2006a). Ang III can enhance renal disease through the overproduction of aldosterone and subsequent development of arterial hypertension and/or to atrial fibrillation (Al-Aloul et al., 2006). Aldosterone which is produced by adrenal cortex maintains blood volume, pressure, and electrolyte balance. It is tightly regulated by renin, an enzyme produced in the juxtaglomerular apparatus of the kidneys. Renin production is elevated by low blood pressure, decreased blood flow to the kidneys or sodium deficiency. In theory, inactivation of Ang III by PRCP might lead to a decrease in blood pressure. However, further studies are needed before claims can be made of a beneficial effect of PRCP on hypertension.

It is well known that cells produce and secrete a large variety of proteases either as proenzymes or activated proteases. Although PRCP can be viewed as a proenzyme based on its primary structure, its post-translational regulation has not been characterized. PRCP is distributed throughout endothelial cells, including lysosome, cytoplasm, and plasma membrane. The membrane bound PRCP activates plasma PK to kallikrein in endothelial cells. The activation of PK is characterized by elevated kallikrein expression along with increased local BK production. Kallikrein-induced BK production causes endothelial cells to produce proinflammatory prostaglandins and vasodilatory nitric oxide (Ngo et al., 2009). Thus, the PRCP-dependent PK activation pathway might be considered as an additional mechanism to counteract the hypertensive activities of both Ang II and Ang III.

Local skeletal muscle ischemia and acidosis are shown to increase the generation of BK and prostaglandins, the two circulating end-products of the PRCP-dependent pathways, Figure 3 (Piepoli et al., 2001). The increased acidotic response during exercise and inflammatory mediators such as BK and prostacyclin have been shown to cause the abnormal exerciserelated symptoms and autonomic responses in congestive heart failure syndrome (Scott et al., 2003). Emerging evidence suggest that the long-term elevated concentrations of NO and prostacyclin may be detrimental and eventually responsible for cardiovascular diseases such as congestive heart disease (Kai C.Wollert and Helmut Drexler, 2004). Needless to say, the reduction of endogenous PGI2 synthesis is associated with the occurrence of cyclic reduction of coronary flow(Tada et al., 1984). Thus, PRCP-dependent Ang 1 -7 and PRCPdependent BK pathways have important biological activities. Altered PRCP expression levels mediates pathophysiological changes in the cardiovascular system.

PK is markedly elevated during pregnancy(Maki and Soga, 1981). Among proteases that metabolize neuropeptide Y 3-36 (NPY3-36, anorexigenic hormone), plasma kallikrein metabolizes $\mathrm{NPY}_{3-36}$ to $\mathrm{NPY}_{3-35}$ (Abid et al., 2009). In addition, specific inhibitor of plasma kallikrein prevents the production of $\mathrm{NPY}_{3-35}$. We find these studies intriguing because elevation of kallikrein should provoke anorectic effect via accelerated inactivation of $\mathrm{NPY}_{3-}$ 36. Recent evidence suggests that there is a link between severe prekallikrein deficiency and pregnancy loss (Dasanu and Alexandrescu, 2009). As mentioned earlier, PRCP activates PK to kallikrein. If PRCP is inhibited/down-regulated, kallikrein levels are lower. Thus, 
disruption of PRCP-dependent PK activation may be a risk factor for pregnancy losses. The inhibitors of both kallikrein and PRCP may be contraindicated during pregnancy. However, further investigations are required to define the safety of these inhibitors.

The activation of POMC is characterized by elevated $\alpha-\mathrm{MSH}_{1-13}$ production. $\alpha-\mathrm{MSH}_{1-13}$ regulates inflammation and food intake, suggesting that it may contribute to tissue damage production. Recently, experimental evidence indicated that PRCP metabolizes $\alpha-\mathrm{MSH}_{1-13}$ to $\alpha-\mathrm{MSH}_{1-12}$ (Wallingford et al., 2009). Mice deficient for PRCP present high blood pressure (Adams G.N et al., 2009), a sustained long-term reduction in food intake, and increased energy expenditure (Wallingford et al., 2009). In humans, hypertension is considered to be a multifactorial disorder. Prcp gene and its variants contribute to hypertension (Wang et al., 2006c; Zhang et al., 2009; Zhu et al., 2010). Rutaecarpine stimulates expression of PRCP in the circulation and small arteries in renovascular hypertensive rats (Qin et al., 2009). Since PRCP variant promotes disease progression (Zhang et al., 2009) in Chinese hypertensive patients and risk of preeclampsia in black and non-black women (Wang et al., 2006b), it is a candidate for pharmacological intervention.

\section{Conclusions and future directions}

In conclusion, PRCP is one of the conserved proteases throughout evolution in vertebrates. In-vitro and in-vivo studies of PRCP, this enzyme serves to generate nitric oxide and prostaglandins. Notably, bradykinin and bradykinin 1-8 are important mediators of pain (Argent et al., 1954) and endotoxin-induced vascular permeability \{Ueno, 1995783 /id\}. BK production is increased in ischemic myocardial tissue (Dell'Italia and Oparil, 1999). They are involved in the control of local blood flow. Although PRCP is less efficient than ACE2induced $\mathrm{NO}$ and prostaglandin generation under pathophysiological conditions, this redundant mechanism has presumably evolved for ischemic remodeling and smooth blood flow (Figure 1 and Figure 3). Overactivation of this mechanism may contribute to myocardial tissue damage or endothelial dysfunction. It inactivates $\mathrm{BK}_{1-8}$, suggesting that PRCP may also reduce marked inflammatory response. It appears that PRCP is fine-tuned to discriminate between physiological and pathophysiological changes. Since cardiomyocytes are unable to proliferate (Lagrand et al., 2000), inactivation of $\mathrm{BK}_{1-8}$ by PRCP may contribute to prevention of tissue damage. Further studies are warranted to evaluate the role of PRCP in cardiovascular system, in particular the heart.

\section{Acknowledgment}

This work was supported by National Institute of Health [NCRR/NIH P20RR021929] to ZSM.

\section{References}

Adams, G.N., LaRusch, G.A., Stavrou, E., Zhou, Y., Nieman, M.T., Jacobs, G.H., Cui, Y., Lu, Y., Jain, M.K., Mahdi, F., Shariat-Madar, Z., Okada, Y., D'Alecy, L.G., and Schmaier, A.H. (2011). Murine prolylcarboxypeptidase depletion induces vascular dysfunction with hypertension and faster arterial thrombosis. Blood 117, 3929-3937.

Baglia, F.A., Shrimpton, C.N., Emsley, J., Kitagawa, K., Ruggeri, Z.M., Lopez, J.A., and Walsh, P.N. (2004). Factor XI interacts with the leucine-rich repeats of glycoprotein Ibalpha on the activated platelet. J. Biol. Chem. 279, 49323-49329. 
Baglia, F.A. and Walsh, P.N. (1998). Prothrombin is a cofactor for the binding of factor XI to the platelet surface and for platelet-mediated factor XI activation by thrombin. Biochemistry 37, 2271-2281.

Billet, S., Aguilar, F., Baudry, C., and Clauser, E. (2008). Role of angiotensin II AT1 receptor activation in cardiovascular diseases. Kidney Int. 74, 1379-1384.

Boric, M.P., Croxatto, H.R., Moreno, J.M., Silva, R., Hernandez, C., and Roblero, J.S. (1998). Kinins mediate the inhibition of atrial natriuretic peptide diuretic effect induced by pepsanurin. Biol. Res. 31, 33-48.

Brasier, A.R., Jamaluddin, M., Han, Y., Patterson, C., and Runge, M.S. (2000). Angiotensin II induces gene transcription through cell-type-dependent effects on the nuclear factor-kappaB (NF-kappaB) transcription factor. Mol. Cell Biochem. 212, 155-169.

Brown, J.J., Fraser, R., Lever, A.F., and Robertson, J.I. (1983). The renin-angiotensin system in congestive cardiac failure: a selective review. Eur. Heart J. 4 Suppl A, 85-87.

Bryant, J.W. and Shariat-Madar, Z. (2009). Human plasma kallikrein-kinin system: physiological and biochemical parameters. Cardiovasc. Hematol. Agents Med. Chem. 7, 234-250.

Burch, G.E. and DePasquale, N.P. (1962). Bradykinin, digital blood flow, and the arteriovenous anastomoses. Circ. Res. 10, 105-115.

Burch, G.E. and DePasquale, N.P. (1963). Bradykinin. Am. Heart J 65, 116-123.

Burrell, L.M., Risvanis, J., Kubota, E., Dean, R.G., MacDonald, P.S., Lu, S., Tikellis, C., Grant, S.L., Lew, R.A., Smith, A.I., Cooper, M.E., and Johnston, C.I. (2005). Myocardial infarction increases ACE2 expression in rat and humans. Eur. Heart J. 26, 369-375.

Chajkowski, S.M., Mallela, J., Watson, D.E., Wang, J., McCurdy, C.R., Rimoldi, J.M., and Shariat-Madar, Z. (2010). Highly selective hydrolysis of kinins by recombinant prolylcarboxypeptidase. Biochem. Biophys. Res. Commun.

Chiu, N. and Reid, I.A. (1997). Role of kinins in basal and furosemide-stimulated renin secretion. J Hypertens. 15, 517-521.

Clerk, A., Cullingford, T.E., Kemp, T.J., Kennedy, R.A., and Sugden, P.H. (2005). Regulation of gene and protein expression in cardiac myocyte hypertrophy and apoptosis. Adv. Enzyme Regul. 45, 94-111.

Croxatto, H.R., Figueroa, X.F., Roblero, J., and Boric, M.P. (1999). Kinin B2 receptors mediate blockade of atrial natriuretic peptide natriuresis induced by glucose or feeding in fasted rats. Hypertension 34, 826-831.

Czokalo-Plichta, M., Skibinska, E., Kosiorek, P., and Musial, W.J. (2001). Kallikrein-kinin system activation and its interactions with other plasma haemostatic components in the coronary artery disease. Rocz. Akad. Med. Bialymst. 46, 209-224.

Deddish, P.A., Skidgel, R.A., Kriho, V.B., Li, X.Y., Becker, R.P., and Erdos, E.G. (1990). Carboxypeptidase $\mathrm{M}$ in Madin-Darby canine kidney cells. Evidence that carboxypeptidase $M$ has a phosphatidylinositol glycan anchor. J Biol. Chem. 265, 15083-15089.

Duan, L., Motchoulski, N., Danzer, B., Davidovich, I., Shariat-Madar, Z., and Levenson, V.V. (2011). Prolylcarboxypeptidase regulates proliferation, autophagy, and resistance to 4-hydroxytamoxifen-induced cytotoxicity in estrogen receptor-positive breast cancer cells. J Biol. Chem. 286, 2864-2876.

Farmer, J.A. (2000). Renin angiotensin system and ASCVD. Curr. Opin. Cardiol. 15, 141-150.

Farmer, J.A. and Torre-Amione, G. (2001). The renin angiotensin system as a risk factor for coronary artery disease. Curr. Atheroscler. Rep. 3, 117-124. 
Foucart, S., Grondin, L., Couture, R., and Nadeau, R. (1997a). Modulation of noradrenaline release by B1 and B2 kinin receptors during metabolic anoxia in the rat isolated atria. Can. J Physiol Pharmacol. 75, 639-645.

Foucart, S., Grondin, L., Couture, R., and Nadeau, R. (1997b). Paradoxical action of desipramine on the modulatory effect of bradykinin on noradrenaline release in a model of metabolic anoxia in rat isolated atria. Can. J Physiol Pharmacol. 75, 646651.

Gailani, D. and Broze, G.J., Jr. (1991). Factor XI activation in a revised model of blood coagulation. Science 253, 909-912.

Gordon, E.M., Ratnoff, O.D., Saito, H., Gross, S., and Jones, P.K. (1980). Studies on some coagulation factors (Hageman factor, plasma prekallikrein, and high molecular weight kininogen) in the normal newborn. Am. J Pediatr. Hematol. Oncol. 2, 213216.

Gurley, S.B., Allred, A., Le, T.H., Griffiths, R., Mao, L., Philip, N., Haystead, T.A., Donoghue, M., Breitbart, R.E., Acton, S.L., Rockman, H.A., and Coffman, T.M. (2006). Altered blood pressure responses and normal cardiac phenotype in ACE2-null mice. J. Clin. Invest 116, 2218-2225.

Hashimoto, K., Hirose, M., Furukawa, S., Hayakawa, H., and Kimura, E. (1977). Changes in hemodynamics and bradykinin concentration in coronary sinus blood in experimental coronary artery occlusion. Jpn. Heart J 18, 679-689.

Hashimoto, K., Mitamura, H., Honda, Y., Kawasumi, S., Takano, T., Kimura, E., and Tsunoo, M. (1979). Changes in blood level of kininogen, prostaglandin $E$ and hemodynamics during experimental acute myocardial ischemia with and without FOY-007. Adv. Exp. Med. Biol. 120B, 403-411.

Hayashi, T., Takai, S., and Yamashita, C. (2010). Impact of the Renin-AngiotensinAldosterone-System on Cardiovascular and Renal Complications in Diabetes Mellitus. Curr. Vasc. Pharmacol.

Hettinger, U., Lukasova, M., Lewicka, S., and Hilgenfeldt, U. (2002). Regulatory effects of salt diet on renal renin-angiotensin-aldosterone, and kallikrein-kinin systems. Int. Immunopharmacol. 2, 1975-1980.

Hooley, E., McEwan, P.A., and Emsley, J. (2007). Molecular modeling of the prekallikrein structure provides insights into high-molecular-weight kininogen binding and zymogen activation. J Thromb. Haemost. 5, 2461-2466.

Jackman, H.L., Tan, F., Schraufnagel, D., Dragovic, T., Dezso, B., Becker, R.P., and Erdos, E.G. (1995). Plasma membrane-bound and lysosomal peptidases in human alveolar macrophages. Am. J Respir. Cell Mol. Biol. 13, 196-204.

Javerzat, S., Franco, M., Herbert, J., Platonova, N., Peille, A.L., Pantesco, V., De, V.J., Assou, S., Bicknell, R., Bikfalvi, A., and Hagedorn, M. (2009). Correlating global gene regulation to angiogenesis in the developing chick extra-embryonic vascular system. PLoS One 4, e7856.

Jia, G., Aggarwal, A., Yohannes, A., Gangahar, D.M., and Agrawal, D.K. (2011). Cross-talk between angiotensin II and IGF-1-induced connexin 43 expression in human saphenous vein smooth muscle cells. J Cell Mol. Med 15, 1695-1702.

Joseph, K., Shibayama, Y., Ghebrehiwet, B., and Kaplan, A.P. (2001). Factor XII-dependent contact activation on endothelial cells and binding proteins $\mathrm{gClqR}$ and cytokeratin 1. Thromb. Haemost. 85, 119-124.

Kai, H., Fukui, T., Lassegue, B., Shah, A., Minieri, C.A., and Griendling, K.K. (1996). Prolonged exposure to agonist results in a reduction in the levels of the Gq/G11 
alpha subunits in cultured vascular smooth muscle cells. Mol. Pharmacol. 49, 96104.

Katori, M. and Majima, M. (2003). The renal kallikrein-kinin system: its role as a safety valve for excess sodium intake, and its attenuation as a possible etiologic factor in saltsensitive hypertension. Crit Rev. Clin. Lab Sci. 40, 43-115.

Katori, M. and Majima, M. (2008). Are all individuals equally sensitive in the blood pressure to high salt intake? (Review article). Acta Physiol Hung. 95, 247-265.

Keularts, I.M., Zivelin, A., Seligsohn, U., Hemker, H.C., and Beguin, S. (2001). The role of factor XI in thrombin generation induced by low concentrations of tissue factor. Thromb. Haemost. 85, 1060-1065.

Kimura, E., Hashimoto, K., Furukawa, S., and Hayakawa, H. (1973). Changes in bradykinin level in coronary sinus blood after the experimental occlusion of a coronary artery. Am. Heart J 85, 635-647.

Kleniewski, J., Dingle, S., and Donaldson, V.H. (1988). Comparison of properties of monoclonal and polyclonal antibodies against the light chain of human high molecular weight kininogen. J. Lab Clin. Med. 111, 93-103.

Koide, T. and Odani, S. (1987). Histidine-rich glycoprotein is evolutionarily related to the cystatin superfamily. Presence of two cystatin domains in the N-terminal region. FEBS Lett. 216, 17-21.

Krankel, N., Katare, R.G., Siragusa, M., Barcelos, L.S., Campagnolo, P., Mangialardi, G., Fortunato, O., Spinetti, G., Tran, N., Zacharowski, K., Wojakowski, W., Mroz, I., Herman, A., Manning Fox, J.E., MacDonald, P.E., Schanstra, J.P., Bascands, J.L., Ascione, R., Angelini, G., Emanueli, C., and Madeddu, P. (2008). Role of kinin B2 receptor signaling in the recruitment of circulating progenitor cells with neovascularization potential. Circ. Res. 103, 1335-1343.

Kumamoto, K., Stewart, T.A., Johnson, A.R., and Erdos, E.G. (1981). Prolylcarboxypeptidase (angiotensinase C) in human lung and cultured cells. J. Clin. Invest 67, 210-215.

Lortie, M., Regoli, D., Rhaleb, N.E., and Plante, G.E. (1992). The role of B1- and B2-kinin receptors in the renal tubular and hemodynamic response to bradykinin. Am. J Physiol 262, R72-R76.

Marceau, F., Gendreau, M., Barabe, J., St-Pierre, S., and Regoli, D. (1981). The degradation of bradykinin (BK) and of des-Arg9-BK in plasma. Can. J. Physiol Pharmacol. 59, 131-138.

Molteni, A. (1982). Considerations of the renin-angiotensin aldosterone system in the pathogenesis of hypertension in infancy. Ann. Clin. Lab Sci. 12, 492-499.

Moreira, C.R., Schmaier, A.H., Mahdi, F., da, M.G., Nader, H.B., and Shariat-Madar, Z. (2002). Identification of prolylcarboxypeptidase as the cell matrix-associated prekallikrein activator. FEBS Lett. 523, 167-170.

Mosher, P., Ross, J., Jr., McFate, P.A., and Shaw, R.F. (1964). Control of coronary blood flow by an autoregulatory mechansim. Circ. Res. 14, 250-259.

Motta, G., Shariat-Madar, Z., Mahdi, F., Sampaio, C.A., and Schmaier, A.H. (2001). Assembly of high molecular weight kininogen and activation of prekallikrein on cell matrix. Thromb. Haemost. 86, 840-847.

Nicholls, M.G. and Robertson, J.I. (2000). The renin-angiotensin system in the year 2000. J. Hum. Hypertens. 14, 649-666.

Odya, C.E., Marinkovic, D.V., Hammon, K.J., Stewart, T.A., and Erdos, E.G. (1978). Purification and properties of prolylcarboxypeptidase (angiotensinase C) from human kidney. J. Biol. Chem. 253, 5927-5931. 
Oishi, T., Ogura, T., Yamauchi, T., Harada, K., and Ota, Z. (1996). Effect of renin-angiotensin inhibition on glomerular injuries in DOCA-salt hypertensive rats. Regul. Pept. 62, 89-95.

Oudart, N. (2005). [The renin-angiotensin system: current data]. Ann. Pharm. Fr. 63, 144-153.

Pawluczyk, I.Z., Tan, E.K., Lodwick, D., and Harris, K.P. (2008). Kallikrein gene 'knockdown' by small interfering RNA transfection induces a profibrotic phenotype in rat mesangial cells. J. Hypertens. 26, 93-101.

Perret-Guillaume, C., Joly, L., Jankowski, P., and Benetos, A. (2009). Benefits of the RAS blockade: clinical evidence before the ONTARGET study. J. Hypertens. 27 Suppl 2, S3-S7.

Pixley, R.A., Espinola, R.G., Ghebrehiwet, B., Joseph, K., Kao, A., Bdeir, K., Cines, D.B., and Colman, R.W. (2011). Interaction of high-molecular-weight kininogen with endothelial cell binding proteins suPAR, gC1qR and cytokeratin 1 determined by Surface Plasmon Resonance (BiaCore). Thromb. Haemost. 105.

Purdon, A.D., Schapira, M., De, A.A., and Colman, R.W. (1985). Plasma kallikrein and prorenin in patients with hereditary angioedema. J. Lab Clin. Med. 105, 694-699.

Ratnoff, O.D. and Saito, H. (1979). Surface-mediated reactions. Curr. Top. Hematol. 2, 1-57.

Reddigari, S.R. and Kaplan, A.P. (1989). Monoclonal antibody to human high-molecularweight kininogen recognizes its prekallikrein binding site and inhibits its coagulant activity. Blood 74, 695-702.

Renshaw, M.A., Ellingsen, D., Costner, B., Benson, J., Heit, J.A., and Hooper, W.C. (2001). Fluorescent multiplex polymerase chain reaction analysis of four genes associated with inpaired fibrinolysis and myocardial infarction. Blood Coagul. Fibrinolysis 12, 245-251.

Ritz, E. (2005). The role of the kidney in cardiovascular medicine. Eur. J. Intern. Med. 16, 321-327.

Savinetskaia, G.A., Golubeva, A.A., Pogoda, T.V., and Generozov, E.V. (2008). [Contribution of rennin-angiotensin-aldosterone system genes and NO synthase gene to the development of arterial hypertension]. Klin. Med. (Mosk) 86, 12-17.

Saxena, P., Thompson, P., d'Udekem, Y., and Konstantinov, I.E. (2011). Kallikrein-kinin system: a surgical perspective in post-aprotinin era. J Surg. Res. 167, 70-77.

Schricker, K., Hegyi, I., Hamann, M., Kaissling, B., and Kurtz, A. (1995). Tonic stimulation of renin gene expression by nitric oxide is counteracted by tonic inhibition through angiotensin II. Proc. Natl. Acad. Sci. U. S. A 92, 8006-8010.

Sealey, J.E., Atlas, S.A., Laragh, J.H., Silverberg, M., and Kaplan, A.P. (1979). Initiation of plasma prorenin activation by Hageman factor-dependent conversion of plasma prekallikrein to kallikrein. Proc. Natl. Acad. Sci. U. S. A 76, 5914-5918.

Shariat-Madar, B., Kolte, D., Verlangieri, A., and Shariat-Madar, Z. (2010). Prolylcarboxypeptidase (PRCP) as a new target for obesity treatment. Diabetes Metab Syndr. Obes. 3, 67-78.

Shariat-Madar, Z., Mahdi, F., and Schmaier, A.H. (2002). Identification and characterization of prolylcarboxypeptidase as an endothelial cell prekallikrein activator. J Biol. Chem. 277, 17962-17969.

Shariat-Madar, Z., Rahimy, E., Mahdi, F., and Schmaier, A.H. (2005). Overexpression of prolylcarboxypeptidase enhances plasma prekallikrein activation on Chinese hamster ovary cells. Am. J. Physiol Heart Circ. Physiol 289, H2697-H2703.

Shariat-Madar, Z. and Schmaier, A.H. (2004). The plasma kallikrein/kinin and renin angiotensin systems in blood pressure regulation in sepsis. J. Endotoxin. Res. 10, 3-13. 
Sharma, J.N. (2009). Hypertension and the bradykinin system. Curr. Hypertens. Rep. 11, 178-181.

Siragy, H.M., Jaffa, A.A., and Margolius, H.S. (1997). Bradykinin B2 receptor modulates renal prostaglandin E2 and nitric oxide. Hypertension 29, 757-762.

Skidgel, R.A., Wickstrom, E., Kumamoto, K., and Erdos, E.G. (1981). Rapid radioassay for prolylcarboxypeptidase (angiotensinase C). Anal. Biochem. 118, 113-119.

Soisson, S.M., Patel, S.B., Abeywickrema, P.D., Byrne, N.J., Diehl, R.E., Hall, D.L., Ford, R.E., Reid, J.C., Rickert, K.W., Shipman, J.M., Sharma, S., and Lumb, K.J. (2010). Structural definition and substrate specificity of the S28 protease family: the crystal structure of human prolylcarboxypeptidase. BMC Struct. Biol. 10, 16.

Sorrells, K. and Erdos, E.G. (1971). Prolylcarboxypeptidase in biological fluids. Adv. Exp. Med. Biol. 23, 393-397.

Sueyoshi, T., Miyata, T., Hashimoto, N., Kato, H., Hayashida, H., Miyata, T., and Iwanaga, S. (1987). Bovine high molecular weight kininogen. The amino acid sequence, positions of carbohydrate chains and disulfide bridges in the heavy chain portion. J. Biol. Chem. 262, 2768-2779.

Suga, K., Ito, K., Tsuru, D., and Yoshimoto, T. (1995). Prolylcarboxypeptidase (angiotensinase C): purification and characterization of the enzyme from Xanthomanas maltophilia. Biosci. Biotechnol. Biochem. 59, 298-301.

Suzawa, Y., Hiraoka, B.Y., Harada, M., and Deguchi, T. (1995). High-performance liquid chromatographic determination of prolylcarboxypeptidase activity in monkey kidney. J. Chromatogr. B Biomed. Appl. 670, 152-156.

Tada, M., Esumi, K., Yamagishi, M., Kuzuya, T., Matsuda, H., Abe, H., Uchida, Y., and Murao, S. (1984). Reduction of prostacyclin synthesis as a possible cause of transient flow reduction in a partially constricted canine coronary artery. J Mol. Cell Cardiol. 16, 1137-1149.

Taketomi, T., Szlam, F., Bader, S.O., Sheppard, C.A., Levy, J.H., and Tanaka, K.A. (2008). Effects of recombinant activated factor VII on thrombin-mediated feedback activation of coagulation. Blood Coagul. Fibrinolysis 19, 135-141.

Tamaoki, J., Sugimoto, F., Tagaya, E., Isono, K., Chiyotani, A., and Konno, K. (1994). Angiotensin II 1 receptor-mediated contraction of pulmonary artery and its modulation by prolylcarboxypeptidase. J. Appl. Physiol 76, 1439-1444.

Tan, F., Morris, P.W., Skidgel, R.A., and Erdos, E.G. (1993). Sequencing and cloning of human prolylcarboxypeptidase (angiotensinase C). Similarity to both serine carboxypeptidase and prolylendopeptidase families. J. Biol. Chem. 268, 16631-16638.

Taquini, A.C., Jr. and Taquini, A.C. (1961). The renin-angiotensin system in hypertension. Am. Heart J. 62, 558-564.

Tatro, J.B. and Reichlin, S. (1987). Specific receptors for alpha-melanocyte-stimulating hormone are widely distributed in tissues of rodents. Endocrinology 121, 1900-1907.

Tatro, J.B., Wen, Z., Entwistle, M.L., Atkins, M.B., Smith, T.J., Reichlin, S., and Murphy, J.R. (1992). Interaction of an alpha-melanocyte-stimulating hormone-diphtheria toxin fusion protein with melanotropin receptors in human melanoma metastases. Cancer Res. 52, 2545-2548.

Uchida, Y. and Murao, S. (1974). Bradykinin-induced excitation of afferent cardiac sympathetic nerve fibers. Jpn. Heart J 15, 84-91.

Varano, D., V, Lansley, S., Tan, A.L., Creaney, J., Lee, Y.C., and Stewart, G.A. (2011). Mesothelial cells activate the plasma kallikrein-kinin system during pleural inflammation. Biol. Chem. 392, 633-642. 
Volpe, M. and De, P.P. (2000). Angiotensin II AT2 subtype receptors: an emerging target for cardiovascular therapy. Ital. Heart J. 1, 96-103.

Volzke, H., Kleine, V., Robinson, D.M., Grimm, R., Hertwig, S., Schwahn, C., Eckel, L., and Rettig, R. (2005). Renin-angiotensin system and haemostasis gene polymorphisms and outcome after coronary artery bypass graft surgery. Int. J. Cardiol. 98, 133-139.

Wallingford, N., Perroud, B., Gao, Q., Coppola, A., Gyengesi, E., Liu, Z.W., Gao, X.B., Diament, A., Haus, K.A., Shariat-Madar, Z., Mahdi, F., Wardlaw, S.L., Schmaier, A.H., Warden, C.H., and Diano, S. (2009). Prolylcarboxypeptidase regulates food intake by inactivating alpha-MSH in rodents. J. Clin. Invest 119, 2291-2303.

Walsh, P.N. and Griffin, J.H. (1981). Platelet-coagulant protein interactions in contact activation. Ann. N. Y. Acad. Sci. 370, 241-252.

Wang, L., Feng, Y., Zhang, Y., Zhou, H., Jiang, S., Niu, T., Wei, L.J., Xu, X., Xu, X., and Wang, $X$. (2006). Prolylcarboxypeptidase gene, chronic hypertension, and risk of preeclampsia. Am. J. Obstet. Gynecol. 195, 162-171.

Wang, S.X., Fan, Z.C., and Tao, Y.X. (2008). Functions of acidic transmembrane residues in human melanocortin-3 receptor binding and activation. Biochem. Pharmacol. 76, 520-530.

Watson, B., Jr., Nowak, N.J., Myracle, A.D., Shows, T.B., and Warnock, D.G. (1997). The human angiotensinase $C$ gene (HUMPCP) maps to 11q14 within $700 \mathrm{~kb}$ of D11S901: a candidate gene for essential hypertension. Genomics 44, 365-367.

Wilop, S., von, H.S., Crysandt, M., Esser, A., Osieka, R., and Jost, E. (2009). Impact of angiotensin I converting enzyme inhibitors and angiotensin II type 1 receptor blockers on survival in patients with advanced non-small-cell lung cancer undergoing first-line platinum-based chemotherapy. J. Cancer Res. Clin. Oncol. 135, 1429-1435.

Yang, B., Li, D., Phillips, M.I., Mehta, P., and Mehta, J.L. (1998). Myocardial angiotensin II receptor expression and ischemia-reperfusion injury. Vasc. Med. 3, 121-130.

Yokosawa, N., Takahashi, N., Inagami, T., and Page, D.L. (1979). Isolation of completely inactive plasma prorenin and its activation by kallikreins. A possible new link between renin and kallikrein. Biochim. Biophys. Acta 569, 211-219.

Zhang Yan, Hong Xiu-mei, Hou-xun, Li Jian-ping, Huo Yong, and Xu Xi-ping (2009). E112D polymorphism in the prolylcarboxypeptidase gene is associated with blood pressure response to benazepril in Chinese hypertensive patients. Chinese Medical Journal 122, 2461-2465.

Zhao, X., Southwick, K., Cardasis, H.L., Du, Y., Lassman, M.E., Xie, D., El-Sherbeini, M., Geissler, W.M., Pryor, K.D., Verras, A., Garcia-Calvo, M., Shen, D.M., Yates, N.A., Pinto, S., and Hendrickon, R.C. (2010). Peptidomic profiling of human cerebrospinal fluid identifies YPRPIHPA as a novel substrate for prolylcarboxypeptidase. Proteomics.

Zhao, Y., Qiu, Q., Mahdi, F., Shariat-Madar, Z., Rojkjaer, R., and Schmaier, A.H. (2001). Assembly and activation of HK-PK complex on endothelial cells results in bradykinin liberation and NO formation. Am. J. Physiol Heart Circ. Physiol 280, H1821-H1829.

Zhu, L., Carretero, O.A., Liao, T.D., Harding, P., Li, H., Sumners, C., and Yang, X.P. (2010). Role of prolylcarboxypeptidase in angiotensin II type 2 receptor-mediated bradykinin release in mouse coronary artery endothelial cells. Hypertension 56, 384-390. 


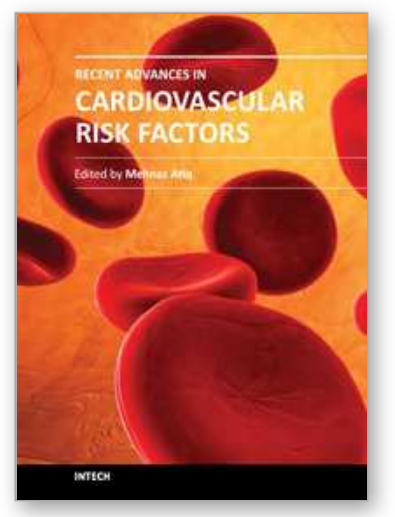

\author{
Recent Advances in Cardiovascular Risk Factors \\ Edited by Prof. Mehnaz Atiq
}

ISBN 978-953-51-0321-9

Hard cover, 522 pages

Publisher InTech

Published online 21, March, 2012

Published in print edition March, 2012

Among the non-communicable diseases, cardiovascular disorders are the leading cause of morbidity and mortality in both the developed and the developing countries. The spectrum of risk factors is wide and their understanding is imperative to prevent the first and recurrent episodes of myocardial infarction, stroke or peripheral vascular disease which may prove fatal or disabling. This book has tried to present an update on risk factors incorporating new research which has thrown more light on the existing knowledge. It has also tried to highlight regional diversity addressing such issues. It will hopefully be resourceful to the cardiologists, general practitioners, family physicians, researchers, graduate students committed to cardiovascular risk prevention.

\title{
How to reference
}

In order to correctly reference this scholarly work, feel free to copy and paste the following:

B. Shariat-Madar, M. Taherian and Z. Shariat-Madar (2012). On the Mechanism of Action of Prolylcarboxypeptidase, Recent Advances in Cardiovascular Risk Factors, Prof. Mehnaz Atiq (Ed.), ISBN: 978953-51-0321-9, InTech, Available from: http://www.intechopen.com/books/recent-advances-in-cardiovascularrisk-factors/on-the-mechanism-of-action-of-prolylcarboxypeptidase

\section{INTECH}

open science | open minds

\section{InTech Europe}

University Campus STeP Ri

Slavka Krautzeka 83/A

51000 Rijeka, Croatia

Phone: +385 (51) 770447

Fax: +385 (51) 686166

www.intechopen.com

\section{InTech China}

Unit 405, Office Block, Hotel Equatorial Shanghai

No.65, Yan An Road (West), Shanghai, 200040, China

中国上海市延安西路65号上海国际贵都大饭店办公楼405单元

Phone: +86-21-62489820

Fax: $+86-21-62489821$ 
(C) 2012 The Author(s). Licensee IntechOpen. This is an open access article distributed under the terms of the Creative Commons Attribution 3.0 License, which permits unrestricted use, distribution, and reproduction in any medium, provided the original work is properly cited. 